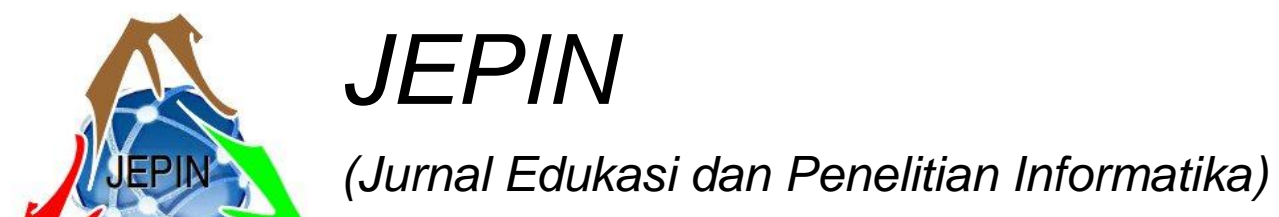

Vol. 6

No. 2

ISSN(e): 2548-9364 / ISSN(p) : 2460-0741

\title{
Prediksi Potensi Kebakaran Hutan dengan Algoritma Klasifikasi C4.5 Studi Kasus Provinsi Kalimantan Barat
}

\author{
Aji Primajaya $^{\# 1}$, Betha Nurina Sari ${ }^{\# 2}$, Ahmad Khusaeri ${ }^{\# 3}$ \\ \#Program Pendidikan Informatika, Universitas Singaperbangsa Karawang \\ Alamat Universitas Jalan HS. Ronggo Waluyo, Puseurjaya, Kecamatan Telukjambe Timur \\ Kabupaten Karawang, Jawa Barat \\ ${ }^{1}$ aji.primajayalstaff.unsika.ac.id \\ ${ }^{3}$ betha. nurinadstaff.unsika.ac.id \\ ${ }^{3}$ ahmad.khusaeri15012@student.unsika.ac.id
}

\begin{abstract}
Abstrak-Algoritma C4.5 merupakan algoritma klasifikasi yang memungkinkan bisa diterapkan untuk studi kasus prediksi potensi kebakaran hutan. Untuk mengetahui penerapan algoritma $\mathrm{C} 4.5$ pada prediksi kebakaran hutan, perlu dilakukan penelitian terkait hal tersebut. Metodologi yang digunakan adalah Knowledge Discovery in Database (KDD). Tahap dari KDD terdiri dari pengumpulan dan pemilihan data, pemrosesan data, transformasi data, pengolahan data dengan algoritma $\mathrm{C} 4.5$ dan terakhir adalah interpretasi serta evaluasi pengetahuan. Percentage split, Cross validation, Use Training Set digunakan sebagai teknik pembagian data training dan testing dengan skenario pesentase dan dipilih model terbaik. Indikator evaluasi yang digunakan adalah akurasi. Penelitian menghasilkan kesimpulan bahwa $\mathrm{C} 4.5$ dengan percentage split $80 \%$ data training dan $20 \%$ data testing menghasilkan akurasi tertinggi yaitu $\mathbf{8 9 , 7 8 5 9 \%}$.
\end{abstract}

Kata kunci - C4.5, Kebakaran Hutan, Prediksi, KDD, Percentage Split

\section{Pendahuluan}

Kebakaran hutan merupakan salah satu bencana alam yang akhir-akhir ini terjadi di indonesia. Seperti diberitakan pada katadata.id, terdapat 1.124 titik panas (hotspot) yang ada di Kalimantan Barat. Data tersebut bersumber dari LAPAN dan diambil sampai dengan 12 agustus 2019. Terdapat banyak kerugian yang dihasilkan dari kebakaran hutan bahkan diperkirakan sampai dengan Rp 221 trilliun berdasarkan sumber dari katadata.id. Kerugian lain yang diakibatkan oleh kebakaran hutan adalah adanya pengurangan jumlah hutan (deforestasi) dan berkurangnya hasil hutan, munculnya pencemaran kabut asap dan emisi, menurunkan kualitas potensi pedasaan [1].

Penanggulangan terhadap kebakaran hutan perlu dilakukan agar bisa diantisipasi atau dihindari terjadinya kebakaran hutan terutama pada daerah yang memiliki potensi rentan terhadap kebakaran hutan. Penerapan berbagai algoritma klasifikasi memungkinkan untuk digunakan dalam prediksi kebakaran hutan sehingga pembuat kebijakan bisa mengetahui daerah rawan kebakaran hutan. Terdapat beberapa penelitian terkait dengan penerapan algoritma klasifikasi untuk prediksi kebakaran hutan.

Penggunaan algoritma klasifikasi untuk prediksi kebakaran hutan dilakukan oleh [2]. [2] menggunakan perpaduan berbagai jenis algoritma untuk memprediksi kebakaran hutan. Algoritma-algoritma tersebut adalah $K$ Means C4.5, K-Means Nä̈ve Bayes, K-Means Random Forest, K-Means Neural Network. Dari keempat algoritme tersebut yang paling memiliki presisi, recall dan F-Mesure tinggi adalah algoritma K-Means dan C4.5. Penelitian lain terkait penggunaan algoritme klasifikasi untuk prediksi kebakaran hutan adalah penelitian [3]. [3] meneliti penggunaan extende ID3 (spatial id3) untuk memprediksi kebakaran hutan. Parameter yang digunakan adalah tataguna lahan, jarak dengan sungai, kepadatan penduduk. Sedangkan atribut taretnya adalah titik panas. Obyek yang digunakan pada penelitian [3] adalah kabupaten Rokan Hilir Provinsi Riau. Akurasi yang dihasilkan dari penelitian tersebut sebesar $74,72 \%$. [4] meneliti tentang interpretasi atau visualisasi pengetahuan hasil dari algoritma spatial id3 dalam bentuk WebGIS. Studi kasus yang digunakan pada penelitian [4] adalah daerah Rokan Hilir Provinsi Riau. Penelitian tersebut menghasilkan WebGIS dengan fitur utama berupa penyajian peta potensi kebakaran hutan. [5] Meneliti tentang penerapan Fuzzy Decision Tree untuk klasifikasi data iklim dan titik api. [6] Meneliti tentang deteksi outlier dengan menggunakan KMeans dan modelnya ditampilkan dalam bentuk WebGIS dengan menggunakan shiny framework. [7] menggunakan time series analysis untuk mengetahui distribusi hotspot, 
dimana studi kasus yag digunakan adalah Kepulauan Meranti. [8] meneliti tentang identifikasi titik api berdasarkan pola sekuensial dan klasifikasi area yang terjadi kebakaran. [9] meneliti tentang perbandingan id3, C4.5, CART, SPRINT, SLIQ pada suatu studi kasus di bidang pendidikan dan ternyata SPRINT memiliki akurasi yang paling baik. [10] meneliti tentang penggunaan teknik datamining dengan dataset meteorologi untuk prediksi kebakaran hutan . [11] meneliti tentang adopsi teknik pruning pada algoritma klasifikasi CART. Pada tahun 2018, [12] melakukan komparasi algoritma dalam mengestimasi daerah yang terkena kebakaran hutan. [13] meneliti tentang penerapan CART dan C4.5 pada suatu studi kasus. Sedangkan [14] meneliti tentang perbandingan antara C4.5 dan CART.

Berdasarkan latar belakang yang telah diuraikan maka telah dilakukan penelitian penerapan algoritma C4.5 pada prediksi kebakaran hutan dengan studi kasus Provins Kalimantan Barat. Penelitian dilakukan untuk mengetahui kualitas model yang dihasilkan dari algoritma C4.5 yang bisa dinilai berdasarkan indikator-indikator evaluasi sesuai dengan metode penelitian yang digunakan.

\section{METODOLOGI}

Metodologi yang digunakan adalah Knowledge Discovery in Database (KDD). Metode tersebut terdiri dari beberapa tahapan di antaranya adalah selecting, preprocessing, transformation, data mining, evaluation, interpretation [15]. Tahapan KDD dapat dilihat pada Gambar 1.

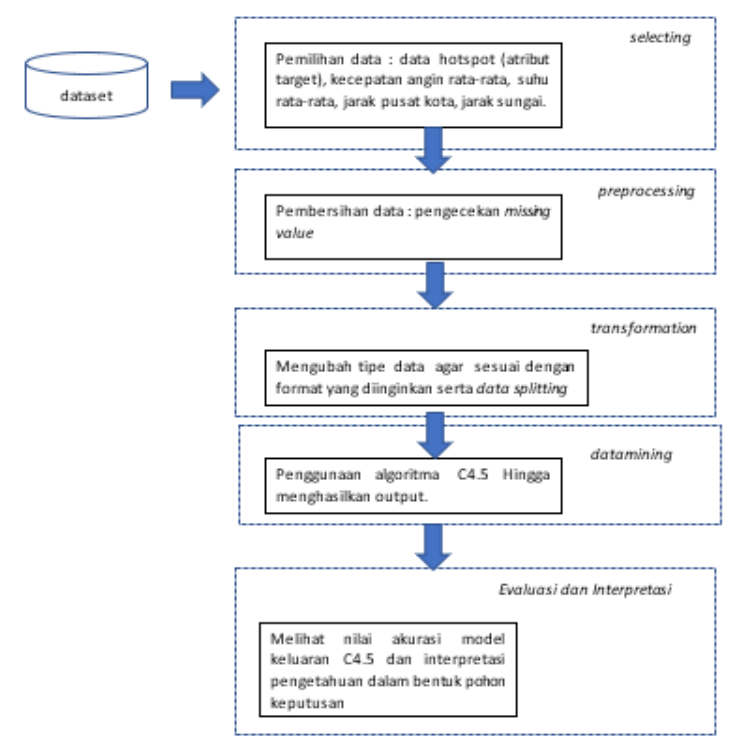

Gambar. 1 Tahapan metodologi Knowledge Discovery in Database

\section{A. Selecting}

Terdapat lima atribut penjelas dan satu atribut target yang dikumpulkan. Atribut penjelas yang dikumpulkan adalah data jarak hotspot dengan pusat kota, jarak hotspot dengan sungai terdekat, kecepatan rata-rata angin pada setiap titik hotspot dan suhu pada setiap titik hotspot serta curah hujan. Sedangkan atribut targetnya adalah hotspot. Data pusat kota didapatkan dari digitasi, data sungai didapatkan dari situs tanahair.indonesia.go.id. Data curah hujan dan kecepatan angin melalui proses interpolasi dengan data sumber berasal dari firms.modaps.nasa.gov. Data false hotspot dibangkitkan dengan menggunakan teknik interpolasi dengan bantuan tools pada Quantum GIS.

\section{B. Preprocessing}

Pada tahap ini data yang didapatkan dilakukan praproses dengan cara mengecek missing value. Apabila terdapat missing value maka dilakukan penanganan dengan cara menghapus data.

\section{Transformation}

Pada tahap ini dilakukan perubahan tipe data dari numerik menjadi kategorikal. Data akan dilakukan klasifikasi dengan menggunakan tools QGIS. Pada tahap ini juga dipecah data menjadi dua bagian yaitu training data dan testing data. Teknik percentage split digunakan pada pemisahan data tersebut.

\section{Data mining}

Menggunakan tools Weka dilakukan pengolahan data dengan algoritm C4.5. Pada weka terdapat modul J4.8 yang bisa digunakan untuk mengimplementasikan algoritma C4.5.

\section{E. Evaluasi dan Interpretasi}

Evaluasi dilakukan dengan memasukkan data testing pada model yang dihasilkan oleh C4.5. Indikator yang dilihat adalah tingkat akurasi dari model yang dihasilkan. Semakin tinggi nilai akurasi maka kualitas prediksi dari model semakin bagus.

\section{HASIL DAN PEMBAHASAN}

Tahapan penelitian pemodelan C4.5 untuk prediksi potensi kebakaran hutan telah dilakukan, penjelasannya sebagai berikut.

\section{A. Selecting}

Atribut target hotspot didapatkan dari situs firms.modaps.eosdis.nasa.gov. Data yang didapatkan dari situs NASA tersebut masih meliputi seluruh wilayah indonesia. Pada proses selecting ini data hotspot yang dipilih adalah khusus untuk wilayah provinsi Kalimantan Barat. Untuk itulah dilakukan proses clipping sesuai dengan batas administrasi dari povinsi Kalimantan Barat. Semua data yang digunakan pada penelitian merupakan data tahun 2018. Gambar 2 merupakan data hotspot seluruh wilayah Indonesia. 


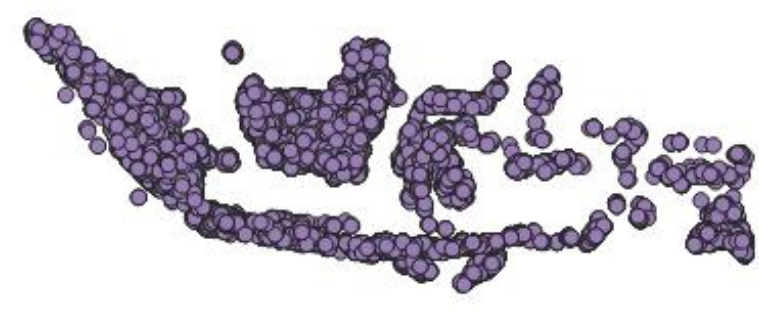

Gambar. 2 Hotspot tahun 2018

Untuk melakukan proses clipping hotspot diperlukan data spasial wilayah Kalimantan Barat. Peta administrasi Kalimantan Barat didapatkan dari situs resmi penyedia dataspasial tanahair.indonesia.go.id. Gambar 3 merupakan peta administrasi Kalimantan Barat.

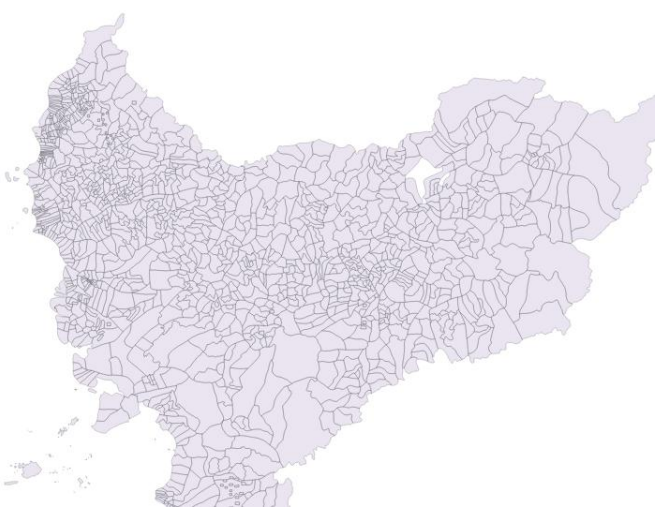

Gambar. 3 Peta administrasi Kalimantan Barat

Setelah mendapatkan peta Kalimantan Barat maka kemudian hotspot di-clip sehingga menghasilkan hotspot yang hanya ada di wilayah Kalimantan Barat. Gambar 4 merupakan hotspot hasil proses clipp dengan menggunakan software QGIS.

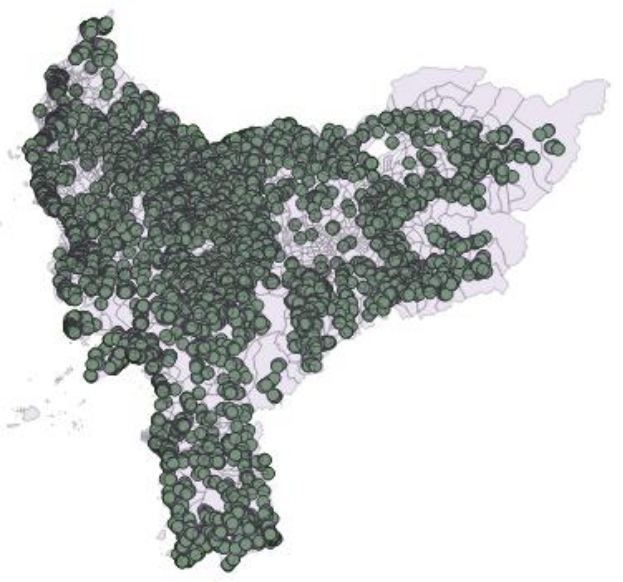

Gambar. 4 Hotspot Kalimantan Barat

Atribut pusat kota didapatkan dengan mencari titik koordinat longitude latitude dari setiap pusat kota tingkat Kabupaten pada Provinsi Kalimantan Barat. Terdapat 14 Kabupaten dan Kotamadya yang digunakan sebagai pusat kota dan data koordinat dicari dengan mengakses layanan koordinat dari distancesto.com. Adapun kabupaten dan kotamadya yang digunakan adalah Bengkayang, Kapuas Hulu, Kayong Utara, Ketapang, kota Pontanak, kabupaten Pontianak, Kubu Raya, Landak, Melawi, Sanggau, Sekadau, dan Sintang. Hasil digitasi lokasi pusat kota disajikan pada gambar 5 .

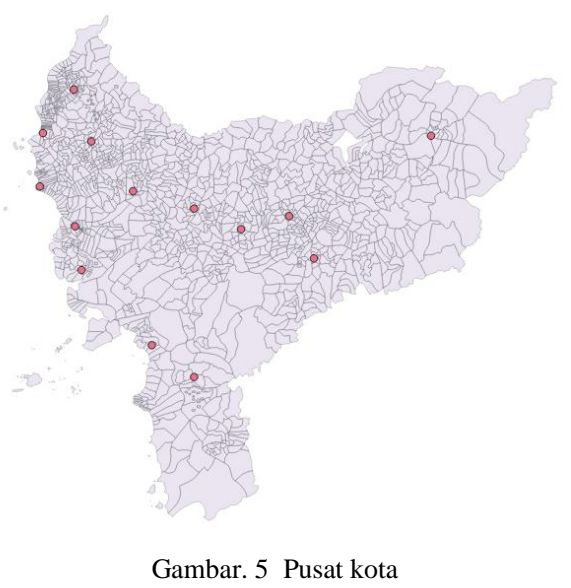

Atribut kecepatan angin, suhu, dan curah hujan didapatkan dengan proses interpolasi data di lima stasiun pengukuran cuaca. Stasiun pengukuran cuaca tersebut adalah Nangapinoh, Paloh, Pangsuma, Supadio, Susilo. Data kecepatan angin, suhu, curah hujan didapatkan dari situs resmi www7.ncdc.noaa.gov/CDO/dataproduct. Setelah dilakukan interpolasi kemudian dilakukan klasifikasi sehingga bisa diketahui nilai atribut curah hujan, suhu dan kecepatan angin dari masing-masing hotspot. Gambar 6 menyajikan hasil interpolasi atribut kecepatan angin.

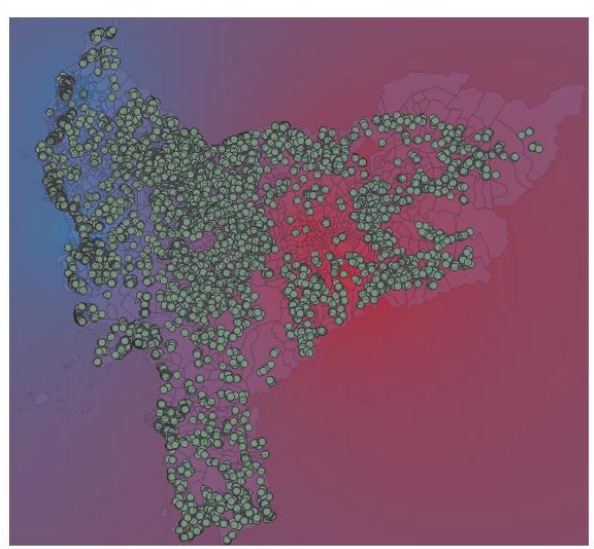

Gambar. 6 Interpolasi kecepatan angin

Pada gambar 6 bisa dilihat bahwa terdapat dua klasifikasi warna secara umum dimana warna yang mendekati biru menandakan kecepatan angin yang tinggi sedangkan mendekati merah kecepatan anginnya rendah. Dari interpolasi tersebut bisa diketahui hotspot yang memiliki kecepatan angin tinggi dan hotspot yang memiliki kecepatan angin rendah. 
Gambar 7 menyajikan interpolasi suhu. Nilai suhu pada gambar 7 bisa dilihat bahwa semakin mendekati warna merah maka nilai suhu semakin kecil sedangkan bila semakin mendekati warna biru maka nilai suhu semakin tinggi. Dari interpolasi tersebut maka bisa dihasilkan klasifikasi dari atribut suhu untuk setiap hotspot. Klasifikasi atribut suhu menjadi tiga kategori yaitu tinggi, rendah, sedang.

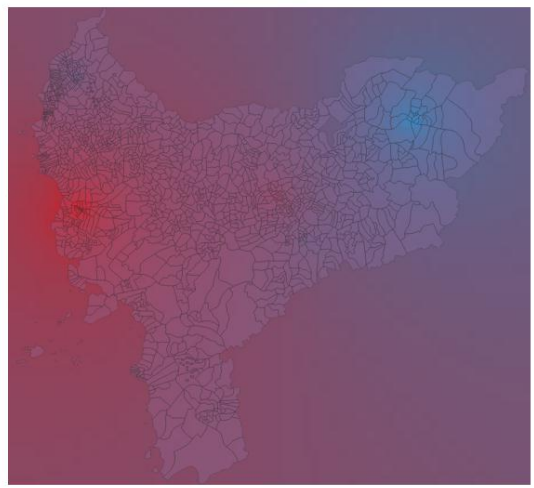

Gambar. 7 Interpolasi suhu

\section{B. Preprocessing}

Praproses (preprocessing) pada penelitian ini adalah melakukan penanganan pada missing value data. Data yang memiliki nilai 9.99 atau 9.999 merupakan data jenis missing value untuk atribut curah hujan, kecepatan angin dan suhu. Penanganannya adalah dengan cara menghilangkan data tersebut. Hal tersebut dilakukan sejak dilakukan penentuan rataan nilai atribut kecepatan angin, suhu dan curah hujan untuk setiap stasiun pengukuran.

Sampai dengan tahap preprocessing, data yang didapatkan hanya memiliki atribut target (hotspot) dengan nilai True. Untuk itu dibangkitkan 1000 data acak hotspot sehingga didapatkan False Hotspot dengan disertai nilai atribut penjelas untuk setiap false hotspot tersebut. Hal ini yang membuat data yang diolah pada penelitian ini sebanyak 8177 data.

Adapun deskripsi dataset yang digunakan dalam penelitian ini dapat dilihat pada tabel 1 .

TABEL I

DESKRIPSI DATASET

\begin{tabular}{|l|l|l|l|}
\hline No & Atribut & Tipe Data & Keterangan nilai \\
\hline 1 & Jarak kota & Nominal & dekat, sedang, jauh \\
\hline 2 & Jarak sungai & Nominal & dekat, sedang, jauh \\
\hline 3 & Kecepatan angin & Nominal & tinggi, rendah \\
\hline 4. & Suhu & Nominal & rendah, sedang, tinggi \\
\hline 5 & hotspot & Nominal & true, false \\
\hline
\end{tabular}

\section{Transformation}

Terdapat dua tahapan dalam hal transformasi yaitu melakukan integrasi data dan konversi format data, proses pembagian data menjadi data training dan data testing.
1) Integrasi dan Konversi Format Data : Data yang sudah didapatkan kemudian diintegrasikan dengan terlebih dahulu memberikan id_hotspot untuk setiap atributnya. Data dengan nilai atribut target true dan false digabung. Setelah itu format data dibuat dalam bentuk .csv agar bisa dimasukkan ke dalam weka 3.9.3 (tools untuk pengolahan data).

2) Pembagian data : Pembagian data menjadi data training dan testing dilakukan dengan menggunakan metode Cross validation, Percentage split dan Use Training Set. Cross validation dipilih 10 Fold, sedangkan percentage split dilakukan skenario 30\%, 40\%, 50\%, 60\%, $70 \%$, 80\% dan 90\%. Masing-masing skenario pembagian data diolah menggunakan algoritma C4.5 dan diamati perbandingan hasil prediksinya. Proses percentage split dilakukan dengan menggunakan tools Weka sehingga secara otomatis akan terkondisi pembagian data tersebut. Secara komposisi data dengan atribut penjelas dengan nilai False merupakan minoritas.

\section{Data mining}

Tahap data mining adalah tahap dimana data diolah menggunakan algoritma C4.5. Tahap data mining ini menghasilkan model klasifikasi berupa pohon keputusan. Pada penelitian ini, dalam penerapan algoritma C4.5 untuk memprediksi hotspot menggunakan modul J4.8 pada Weka versi 3.9.3. Pada gambar 8 dapat dilihat hasil terbaik dari pemodelan $\mathrm{C} 4.5$ berupa pohon keputusan.

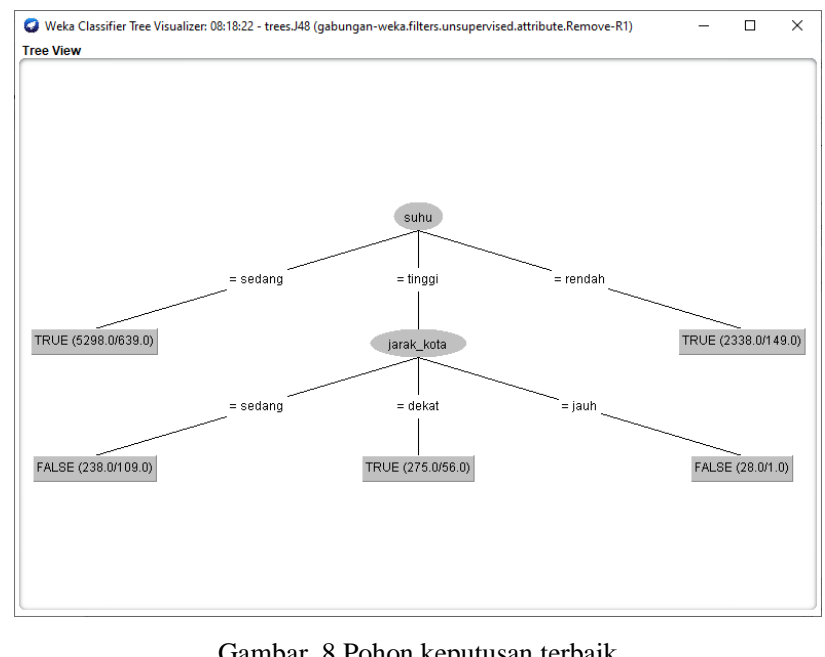

Model terbaik didapatkan dari pembagian data dengan teknik percentage split dengan komposisi $80 \%$ data training dan $20 \%$ data testing. Akurasi yang didapatkan sebesar 89,7859 \%. Selengkapnya terkait perbandingan evaluasi disampaikan dalam subbab evaluasi.

Model yang dihasilkan tersebut juga dapat ditampilkan melalui rule atau aturan yang mudah dipahami. Adapun hasil rule dari pohon keputusan terbaik dapat dilihat pada Gambar 9. 


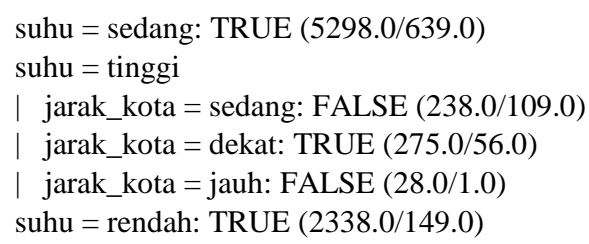

Gambar 9. Rule dari pohon keputusan terbaik

\section{E. Evaluasi dan Interpretasi}

Interpretasi pengetahuan disajikan dengan menggunakan pohon keputusan biner seperti yang disajikan pada gambar 9. Dari pohon keputusan biner tersebut bisa di-generate rule. Ada lima rule atau aturan yang dihasilkan dalam memprediksi hotspot di provinsi Kalimantan Barat, yaitu:

1. Jika suhu sedang maka hotspot True

2. Jika suhu tinggi dan jarak kota sedang maka hotspot False

3. Jika suhu tinggi dan jarak kota dekat, maka hotspot True

4. Jika suhu tinggi dan jara kota jauh, maka hotspot False

5. Jika suhu rendah maka hotspot True

Evaluasi model digunakan indikator akurasi disajikan perbandingan untuk skenario pada tabel 1 .

TABEL II

HASIL EVALUASI

\begin{tabular}{|l|c|}
\hline \multicolumn{2}{|c|}{ Hasil Evaluasi } \\
\hline \multicolumn{1}{|c|}{ Metode } & Akurasi \\
\hline Use Training Set & $88,331 \%$ \\
\hline $\begin{array}{l}\text { Crossvalidation } \\
\mathrm{k}=10 \text { fold }\end{array}$ & $88,331 \%$ \\
\hline \multicolumn{2}{|c|}{ Percentage Split } \\
\hline $\begin{array}{l}\text { Training 90\% } \\
\text { Testing 10\% }\end{array}$ \\
\hline $\begin{array}{l}\text { Training 80\% } \\
\text { Testing 20\% }\end{array}$ \\
\hline $\begin{array}{l}\text { Training 70\% } \\
\text { Testing 30\% }\end{array}$ \\
\hline $\begin{array}{l}\text { Training 60\% } \\
\text { Testing 40\% }\end{array}$ \\
\hline $\begin{array}{l}\text { Training 50\% } \\
\text { Testing 50\% }\end{array}$ \\
\hline $\begin{array}{l}\text { Training 40\% } \\
\text { Testing 60\% }\end{array}$ \\
\hline $\begin{array}{l}\text { Training 30\% } \\
\text { Testing 70\% }\end{array}$ \\
\hline
\end{tabular}

IV. KESIMPULAN

Semua Berdasarkan hasil penelitian maka algoritma C4.5 dengan skenario percentage split $80 \%$ data training dan $20 \%$ data testing mampu menghasilkan akurasi terbaik sebesar $89,7859 \%$.

\section{UCAPAN TERIMA KASIH / ACKNOWLEDGMENT}

Tim peneliti mengucapkan terima kasih kepada kementrian melalui hibah Penelitian Dosen Pemula.

\section{REFERENSI}

[1] L. Tacconi, "Kebakaran Hutan di Indonesia : Penyebab, Biaya dan Implikasi Kebakaran," in CIFOR Occasional Paper, 2003, paper No 38(i).

[2] C. A. Sugianto, "Analisis Komparasi Algoritma Klasifikasi Untuk Menangani Data Tidak Seimbang Pada Data Kebakaran Hutan," Techno.COM., vol. 14, pp. 336-342, Nov. 2015.

[3] I. S. Sitanggang, R. Yakoob, N. Mustapha, A. A. B. Nuruddin, "An Extended ID3 Decision Algorithm for Spatial Data," in Proc. International Conference in Spatial Datamining and Geographical Knowledge Services, 2011, p. 48-53.

[4] A. Primajaya, I. S. Sitanggang, L. Syaufina, "Visualization of Spatial Decision Tree For Predicting Hotspot Occurrence in Land and Forest in Rokan Hilir District Riau," in Proc. IOP Conf. Ser.: Earth Environment. Science, 2017, p. 1-8.

[5] A. Akbar, "Pruning Pada Fuzzy Decision Tree Dalam Klasifikas Data Iklim dan Titik Api di Daerah Tjilik Riwut, Palangkaraya, Kalimantan Selatan," S. Eng. thesis, Institut Pertanian Bogor, Bogor, Indonesia, Juni 2012

[6] A. M. Y. A. Suci, I. S. Sitanggang, "Web-Based Aplication for Outliers Detection on Hotspot Data Using K-Means Algorithm and Shiny Framework," in Proc. IOP Conf. Ser.: Earth Environment. Science, 2016, p. 1-8.

[7] T. Turmudi, P. Kardono, P. Hartanto, Y. Arditasari. "Forest and Land Fire Prevention Through The Hotspot Movement Pattern Approach," in Proc. IOP Conf. Ser.: Earth Environment. Science, 2018, p. 1-8.

[8] N. Istiqomah, I. S. Sitanggang, L. Syaufina. "Fire Spot Identification Based on Hotspot Sequential Pattern And Burn Area Classification,” BIOTROPIA, vol. 25, pp. 147-155, 2018.

[9] A. Priyam, Abhijeet, R. Gupta, A. Rathee, S. Srivastava "Comparative Analysis of Decision Tree Classification Algorithms," International Journal Of Current Engineering and Technology, vol. 3, pp. 334-337, Juni 2013.

[10] P. Cortez, A. Morais. "A Datamining Approach to Predict Fores Fire Using Meteorological Data," Information System, pp. 1-12, 2007.

[11] M. Budi, R. Karyadin, S. H. Wijaya. "Perbandingan Algoritme Pruning pada Decision Tree yang dikembangkan Dengan Algoritme CART", Jurnal Ilmiah Ilmu Komputer, Vol. 15, pp. 7 13 , Desember 2010

[12] Fitriyani, R. Sanjaya, "Komparasi Algoritme LR, K-NN dan SVM untuk Estimasi Area Kebakaran Hutan", Jurnal Ilmiah Ilmu Komputer, Vol. 15, pp. 7-13, Desember 2010

[13] I. Rahmayuni, "Perbandingan Performansi Algoritma C4.5 dan CART Dalam Klasifikasi Data Nilai Mahasiswa Prodi Teknik Komputer Politeknik Negri Padang", Jurnal TEKNOIF, Vol. 2, pp. 40-46, April 2014

[14] D. Alverina, A. R. Chrismanto, R. G. Santosa, "Perbandingan Performansi Algoritma C4.5 dan CART Dalam Memprediksi Kategori Indeks Prestasi Mahasiswa", Jurnal Teknologi dan Sistem Komputer, Vol. 6, pp. 76-83, April 2018

[15] S. Widaningsih, "Perbandingan Metode Datamining untuk Prediksi Nilai dan Waktu Kelulusan Mahasiswa Prodi Teknik Informatika dengan Algoritma C4.5, Naïve Bayes, KNN, dan SVM”, Jurnal Tekno Insentif, Vol. 13, pp. 16-25, April 2019 